\title{
Research as an event: a novel approach to promote patient-focused drug development
}

This article was published in the following Dove Press journal:

Patient Preference and Adherence

\section{Jui-Hua Tsai \\ Ellen Janssen \\ John FP Bridges}

Department of Health Policy and Management, Johns Hopkins Bloomberg School of Public Health, Baltimore, MD, USA
Correspondence: Jui-Hua Tsai Department of Health Policy and Management, Johns Hopkins Bloomberg School of Public Health, 624 North Broadway Hampton House 69I, Baltimore, MD 21205, USA

$\mathrm{Tel}+\mathrm{I} 4105025968$

Fax +14106149152

Email jtsai24@jhmi.edu

\begin{abstract}
Patient groups are increasingly engaging in research to understand patients' preferences and incorporate their perspectives into drug development and regulation. Several models of patient engagement have emerged, but there is little guidance on how to partner with patient groups to engage the disease community. Our group has been using an approach to engage patient groups that we call research as an event. Research as an event is a method for researchers to use a community-centered event to engage patients in their own environment at modest incremental cost. It is a pragmatic solution to address the challenges of engaging patients in research to minimize patients' frustration, decrease the time burden, and limit the overall cost. The community, the event, and the research are the three components that constitute the research as an event framework. The community represents a disease-specific community. The event is a meeting of common interest for patients and other stakeholders, such as a patient advocacy conference. The research describes activities in engaging the community for the purpose of research. Research as an event follows a six-step approach. A case study is used to demonstrate the six steps followed by recommendations for future implementation.
\end{abstract}

Keywords: patients' perspectives, decision making, drug approval, patient engagement, patient organization, patients' preference

\section{Introduction}

Understanding and incorporating the patients' perspectives in regulatory processes have become increasingly important. ${ }^{1-3}$ The 21 st Century Cures Act stresses the use of patients' experience and preference to assist the regulatory review. ${ }^{4}$ Patient-focused drug development (PFDD), commissioned under the Prescription Drug User Fee Act V (PDUFA V), recognizes the value of patients' perspective and purposefully elicits patients' input to inform regulatory benefit-risk assessment. ${ }^{5}$ PDUFA VI builds upon the efforts of PFDD, further highlighting the patients' role in drug development. ${ }^{6}$ The commitment of the USA is mirrored by parallel efforts in Europe, which is part of a larger movement to engaging patients and relevant stakeholders in the decisionmaking process. ${ }^{7,8}$

Although the PFDD's efforts have been fruitful in eliciting patients' perspective, there is uncertainty surrounding the patient engagement strategy for PFDD moving forward. ${ }^{5}$ Several existing models of patient engagement could provide guidance to the PFDD efforts. The patient-centered outcomes research (PCOR) model provides principles to engage patients in PCOR,${ }^{9}$ which could provide insight for the key elements and standards for patient engagement in PFDD. The Community-Based Participatory Research (CBPR) model is a continuous engagement process where researchers partner with the community to achieve a common goal. ${ }^{10,11}$ PFDD builds 
partnership with patients, caregivers, patient advocates, and other stakeholders in the disease community to better understand patients' perspectives. The Patient and Community Engagement Research (PaCER) model advocates the patients as project leaders assisting in driving the research, ${ }^{12}$ putting patients in the front and center of the effort. Similarly, PFDD relies on patients voicing their perspectives and taking a center stage. These models have been implemented and fueled the discussion of patient engagement in research, but these efforts are often not led by patient advocacy organizations.

Patient advocacy organizations have been recognized by the US Food and Drug administration (FDA) as the useful sources in collecting patients' perspectives, evident by their heavy involvement in the PFDD. ${ }^{5,13,14}$ More recently, the FDA established an initiative to invite patient advocacy groups to discuss and to advance its patient engagement efforts. ${ }^{15}$ Over the years, the function of patient advocacy organizations has evolved from providing emotional support for the patients and families to advocate for research, generate scientific evidence, and influence policy change. ${ }^{16-19}$ Patient advocacy groups have a distinctive perspective in driving the patient engagement research. ${ }^{20}$ They understand the disease community and were able to identify research questions most relevant to the community. ${ }^{18,21,22}$ They also have access to a large number of potential participants, including patients and other stakeholders. ${ }^{21}$ The advantages have allowed the patient groups to take on a prominent role in the PFDD, such as when the FDA encouraged patient organizations to conduct externally led PFDD meetings and invited a rare disease patient organization to develop the first draft guidance for industry submissions. ${ }^{14,19}$

We recognize that patient groups can be an advantageous partner to engage patients in research. However, approaches to best engage patient groups in research have not been widely explored. This article describes a model for patient groups and researchers to form a partnership and achieve a common research goal. This model represents an efficient framework to engage patients in research and may help to incorporate the patient voice in regulatory development to further advance the PFDD.

\section{Benefits and challenges of current approaches}

Patient engagement in research has been acknowledged as critical and beneficial to health-related research. ${ }^{9,23}$ Researchers have employed methods such as surveys, interviews, and focus groups. ${ }^{23-25}$ They have engaged patients to facilitate the designs of study protocols, refine the instrument, interpret the study results, and disseminate the findings. ${ }^{26,27}$ Engaged patients lead to an increase in enrollment rates and a decrease in attrition rates in studies, ${ }^{23,28}$ which improve the impact of the study. When involving the patients in the process of the study design, the outcomes become more relevant and meaningful to the patients and the associated disease community. ${ }^{29,30}$ Furthermore, patient participation helps diminish the cultural and language barriers to dissemination and facilitates the interpretation and translation of study results. ${ }^{31}$

Patient engagement comes with certain challenges, and strategies are needed to advance PFDD. ${ }^{5}$ The additional time and funding required for patient engagement are challenges that are present in the current practices. ${ }^{23}$ Other barriers include the procedural requirements for training, transportation, and attendance, which may lead to patient frustration over the prolonged process of participation. ${ }^{23,32,33}$ Other fundamental problems exist, such as where and how to recruit patients and other stakeholders to participate. Clinicians may be hesitant to share patient information due to the sensitive nature of sharing clinical information as well as the additional time and procedural burden to collaborate in a study. As an alternative, the Internet has emerged as a cost-effective way to recruit patients in large-scale research. Researchers recruit through the web using disease registries, online social media, or lists of patient's e-mail contacts provided by relevant patient groups. However, online surveys do not always yield a favorable response rate when compared with paper surveys. ${ }^{34}$ The challenges for researchers to engage patients in research are largely centered on recruitment, while patient groups interact with patients and the community they serve on a regular basis, which presents an opportunity for both parties.

\section{Research as an event}

Our group used an approach that we call research as an event to engage patients through partnering with patient groups. Research as an event allows patient groups to partner with researchers and use a community-centered event to engage patients and other stakeholders in their own environment with little additional cost for the researchers to plan and execute the event. The event is planned not for the purpose of research; rather, the research accommodates the cause and the format of the event. It is a pragmatic approach to lower the resources required (eg, time, budget, and transportation) for engaging patients in research, while increasing the likelihood of researchers including patients in the research process. Research as an event is considered to be less resource 
intensive for both the patient and researcher since it is an add-on to a preexisting event.

\section{The community}

The community is defined as a group of patients, caregivers, and/or other stakeholders with a shared common interest, such as a patient group or a disease community. In research as an event, a patient group partners with the researchers to engage the community. Collaborating with a patient group allows researchers to access the communication channels of the partnering organization and locate the influential leaders in the community. Collaborating with researchers allow patient groups to answer research questions important to the community in a scientific rigorous manner so that the results can be applied PFDD. ${ }^{25}$

Community leadership buy-in is an important factor in the success of research as an event. Buy-in could come from leadership of the patient group or from active community members. Leadership has been identified as an important factor to influence the effectiveness of a community-related partnership. ${ }^{35}$ Leadership can facilitate the partnership by mobilizing community members and administering relevant resources to advance the agenda of research as an event. ${ }^{35}$ Leadership can also communicate the relevance of the study to the community and increase the validity of the study, which would help build rapport and invite participants to take part in the study. ${ }^{36}$ Support from the leadership reduces the time and resources required for trust building with individual patients, ${ }^{37}$ which is critical since the interaction between the researchers and participants is restricted by the limited timeframe of the event.

\section{The event}

The event is defined as a planned meeting usually organized by the patient group or the community that includes a venue, supporting staff, and resources for recruitment. In an ideal setting, the motivation of the participants attending the conference aligns with the purpose of the research for research as an event. Study participants have been shown to participate only if they identify with the relevance of the study. ${ }^{36}$ A suitable venue would be a community-centered event that aims to promote research and inform policy change, such as a patient advocacy group conference. The duration and the agenda of the event are also important in research as an event. When the event is short (less than a day), and the activities are clustered (minimal coffee breaks or network sessions), participants may have to choose between participating in research activities or the event activities that they came for.

\section{The research}

The research describes activities in engaging the community for the purpose of research. Research as an event is a vehicle for researchers to partner with patient groups to develop a community-relevant research question and achieve a common research goal. Researchers should tailor their research activities to accommodate the event to maximize patients' access to the research. Researchers engage the participants at their convenience in research as an event, reducing the opportunity cost of time and travel to a research facility. $23,32,33,36,38$ Research as an event as an approach can address the main challenges of engaging patients in research, including patient frustration over the study procedure, time burden on both the researchers and patients, and budget constraint for recruitment and conducting research activities.

\section{The six steps: a stepwise guideline for implementing research as an event}

Through the conceptualization of research as an event and practical experiences of executing research as an event, we devised a six-step guideline to provide directions on how to implement research as an event. There are six steps for the design and execution of research as an event, including determine research partnership, assess communication channels, identify compatible event, plan according to event, engage through presence, and give and receive feedback.

Determining research partnership (step 1) allows the disease community and the research team to connect and establish first contact. Research as an event can be initiated by an organization in the disease community or by a research team interested in engaging patients in research. Research as an event works best when prior engagement between different members of the community exists. The organizational partner or researchers assess and locate the communication channels of the organization (step 2) for later outreach. Once the researchers and the community connect and agree to a common objective and research question, the researchers and the community will then jointly identify a compatible event (step 3). The compatibility of the event will contribute to the execution of research as an event.

Researchers should plan the research activities according to the event agenda (step 4) and consider the convenience of the participants. The researchers can reach the potential study participants through preidentified and well-planned communication channels located through assessing communication channels (step 2). The researchers should be on-site and reachable at the time of the event so they can engage 
through presence (step 5) and maximize their accessibility to event participants. Whether the research as an event achieved the objective agreed upon by the community can be evaluated and reported through give and receive feedback (step 6). It is critical to provide information about the effectiveness and outcome of the patient engagement as perceived by the event attendees, the patient group, and the researchers.

\section{Case study: partnering with the Foundation for Prader-Willi Research (FPWR)}

Our group has used research as an event in several of our studies and achieved our research objectives. The following case study is a demonstration of using the six steps to conduct research as an event to engage patients and other stakeholders in research. The FPWR is a patient advocacy organization that was established in 2003 to advance research to benefit the Prader-Willi syndrome (PWS) community. ${ }^{39}$ PWS is a rare genetic disorder, with the most prominent symptoms presented as insatiable appetite, obesity, developmental delay, and emotional tantrums. ${ }^{40,41}$ FPWR has conducted their own research and has provided funding to researchers to achieve their goal. However, they are limited in capacity and expertise to produce scientific rigorous research that would be in compliance with current regulatory standards. Hence, FPWR reached out with the intent in using advanced research methods to elicit the treatment preference of the PWS community to inform regulatory decisions.

FPWR and our group decided to use research as an event to pretest and pilot a survey to measure PWS caregiver preference. We filed an Institutional Reviewer Board (IRB) application to pilot and pretest the survey instrument while planning the event, which was deemed exempt from human subjects review by the Johns Hopkins School of Public Health IRB (IRB00007440). We assembled a team of researchers from Johns Hopkins with prior experience executing research as an event and expertise in preference elicitation. The research team partnered with FPWR, which has long-standing ties to the PWS patient community. FPWR and the research team determined that the 2016 Annual FPWR Family Conference was a fitting venue for research as an event. The attendees of the conference were mostly parents caring for PWS individuals and researchers and clinicians working in the field of PWS. The goal of the conference was to connect, disseminate knowledge, and promote PWS research.

FPWR introduced the study to conference participants through the preconference e-mails sent out to the conference participants. No incentive was given for participation of the study. FPWR leadership demonstrated their support by connecting the researchers to the attendees personally. They highlighted the credibility of the research team and the value of the research to the PWS community. Researchers set up an information desk at the main entrance to the conference room, which provided good visibility and easy access to conference attendees. The participants could engage with researchers at the information booth to learn about the study or to participate in on-site pretest interviews. Researchers also included a survey in the registration package to recruit potential participants and allowed the participants to return the survey at any time during the conference.

The research goal was exceeded with respect of pretesting and piloting the survey. No adverse event was reported. Participants were motivated beyond compensation and expressed interest in participating in future studies. They openly stated that they would prefer to engage with on-site researchers compared to answering an online survey, which is consistent with evidence supporting a personal approach in recruitment. ${ }^{42}$ In one participant's own words, "the more personal you can make it, the more response you're going to get." A summary of the six-step model, the case study, and the lessons learned is documented in Table 1.

\section{Discussion}

Our group considers research as an event to be a way for researchers to engage patients in research through partnering with patient groups. We have implemented this approach in our field of study and achieved our research objectives. We have organized and executed research as an event in other patient group meetings and will continue to explore the applications of research as an event. Engaging patients and other stakeholders in the research process brings enormous value to the research and the community it serves. ${ }^{43,44}$

Our group has discovered that research as an event is an effective model to partner with patient groups and engage patients in research. Currently, there is no formal evaluation process to examine the execution and results of research as an event. A committee consisting of patients, caregivers, clinicians, and research as event researchers should identify performance measures and develop standards relating to cost, enrollment rate, survey completion rate, and participant satisfaction metrics. This measurement framework can be applied to standardize research as an event and provide improvements to the six-step guideline. As the FDA moves to standardize the methods used for collecting meaningful patient input, a framework for research as an event is essential to ensure quality of the evidence generated to inform PFDD. ${ }^{3,5,6}$ 
Table I The six steps: an implementation guide for research as an event

\begin{tabular}{|c|c|c|c|}
\hline Six steps & Six-step guideline & Actions & Lessons learned \\
\hline $\begin{array}{l}\text { Determine } \\
\text { research } \\
\text { partnership }\end{array}$ & $\begin{array}{l}\text { Determining the research partnership } \\
\text { allows the organizational partner } \\
\text { and the researchers to connect and } \\
\text { establish contact. It is initiated by an } \\
\text { organization in the disease community } \\
\text { or by a research team interested in } \\
\text { engaging patients in research }\end{array}$ & $\begin{array}{l}\text { The FPWR reached out to researchers } \\
\text { at Johns Hopkins seeking its expertise in } \\
\text { patient's preference and its experience } \\
\text { in collaborating with patient groups } \\
\text { to support the patient-focused drug } \\
\text { development }\end{array}$ & $\begin{array}{l}\text { Research partnership does not have to } \\
\text { be initiated by research organizations. } \\
\text { Patient advocacy groups interested in } \\
\text { research can actively seek out research } \\
\text { organization to collaborate on research } \\
\text { questions relevant to the disease } \\
\text { community }\end{array}$ \\
\hline $\begin{array}{c}\text { Assess } \\
\text { communication } \\
\text { channels }\end{array}$ & $\begin{array}{l}\text { Research as an event works best when } \\
\text { prior engagement within the disease } \\
\text { community exists. The organizational } \\
\text { partner or researchers locate and } \\
\text { assess the prior engagement patterns } \\
\text { and communication channels for later } \\
\text { outreach }\end{array}$ & $\begin{array}{l}\text { The FPWR is deeply connected with the } \\
\text { PWS community. The FPWR has reached } \\
\text { the PWS families in the community in } \\
\text { the past with an e-mail registry list and } \\
\text { regular community-centered events }\end{array}$ & $\begin{array}{l}\text { Patient advocacy organizations with } \\
\text { strong ties to the community with } \\
\text { established engagement channels and } \\
\text { prior engagement history can facilitate the } \\
\text { communication and provide credibility to } \\
\text { the research }\end{array}$ \\
\hline $\begin{array}{l}\text { Identify } \\
\text { compatible } \\
\text { event }\end{array}$ & $\begin{array}{l}\text { Once the researchers and the } \\
\text { community connect and define a } \\
\text { common goal, the researchers will } \\
\text { select a suitable event based on input } \\
\text { from the community. The event is } \\
\text { usually preplanned and not conducted } \\
\text { only to satisfy the aim for research }\end{array}$ & $\begin{array}{l}\text { The FPWR identified the FPWR annual } \\
\text { family conference as the ideal venue for } \\
\text { research as an event. FPWR organized } \\
\text { the family conference to provide social } \\
\text { support to the families and facilitate } \\
\text { research. Resources for recruitment, } \\
\text { supporting staff, and venue have been } \\
\text { allocated to the event }\end{array}$ & $\begin{array}{l}\text { Patient groups often organize regular } \\
\text { community-centered meetings to engage } \\
\text { the patients and families and to advance } \\
\text { research, which aligns with the purpose } \\
\text { of research as an event. Resources that } \\
\text { can be used to facilitate research activities } \\
\text { often overlap with the resources that are } \\
\text { used to conduct the event }\end{array}$ \\
\hline $\begin{array}{l}\text { Plan } \\
\text { according to } \\
\text { event }\end{array}$ & $\begin{array}{l}\text { The research activities should be } \\
\text { planned according to the flexibility } \\
\text { of the event and the convenience of } \\
\text { the participants. The researchers can } \\
\text { reach the potential study participants } \\
\text { through preidentified communication } \\
\text { channels in step } 2\end{array}$ & $\begin{array}{l}\text { The research team met with conference } \\
\text { staff to understand the event structure } \\
\text { and plan the best way to reach the } \\
\text { participants, such as including the survey } \\
\text { in the registration package to disseminate } \\
\text { efficiently. Information about the study } \\
\text { was sent out through preconference } \\
\text { announcements through FPWR's network }\end{array}$ & $\begin{array}{l}\text { Conference staff can be a good resource } \\
\text { for the researchers to tailor the research } \\
\text { activities to the event and increase the } \\
\text { access of the patients to the researchers. } \\
\text { Resource input is not needed to establish } \\
\text { new communication channels when prior } \\
\text { communication patterns exist }\end{array}$ \\
\hline $\begin{array}{l}\text { Engage } \\
\text { through } \\
\text { presence }\end{array}$ & $\begin{array}{l}\text { The researchers should be on-site, } \\
\text { reachable, and ready to engage } \\
\text { at the time of the event. Multiple } \\
\text { communication channels or additional } \\
\text { assistance (such as an interpreter) may } \\
\text { be used to facilitate the encounter and } \\
\text { further the engagement }\end{array}$ & $\begin{array}{l}\text { An information booth was set up in front } \\
\text { of the main exit of the conference room. } \\
\text { At least one researcher was present } \\
\text { at the information booth at all times } \\
\text { during the conference to interact with } \\
\text { participants. Researches engaged the } \\
\text { conference participants through in-depth } \\
\text { interviews and pilot survey }\end{array}$ & $\begin{array}{l}\text { Researchers on-site allow the participants } \\
\text { to engage them face to face. It also } \\
\text { offers the participants an opportunity } \\
\text { to communicate with the researchers } \\
\text { and learn more about the study. Study } \\
\text { participants provided positive feedback } \\
\text { about the engagement process }\end{array}$ \\
\hline $\begin{array}{l}\text { Give and } \\
\text { receive } \\
\text { feedback }\end{array}$ & $\begin{array}{l}\text { Feedback on the research activities } \\
\text { and the facilitation of the community } \\
\text { should be communicated. A well- } \\
\text { organized research as an event } \\
\text { should achieve the goal agreed by the } \\
\text { community and researchers while } \\
\text { optimizing the available resource }\end{array}$ & $\begin{array}{l}\text { Participants offered positive feedback } \\
\text { about research as an event through } \\
\text { the postsurvey debrief interviews. } \\
\text { The research team and the patient } \\
\text { organization had an informal feedback } \\
\text { session to discuss the results and } \\
\text { implications of the research as an event }\end{array}$ & $\begin{array}{l}\text { Research as an event is regarded } \\
\text { favorably by the participants as a feasible } \\
\text { method to engage patients and other } \\
\text { stakeholders in research. It is also a way } \\
\text { for patient advocacy groups to bring } \\
\text { in researchers to achieve a common } \\
\text { research objective }\end{array}$ \\
\hline
\end{tabular}

Abbreviations: FPWR, Foundation for Prader-Willi Research; PWS, Prader-Willi syndrome.

Research as an event provides a unique opportunity for patient groups to engage experienced researchers to produce scientific rigorous studies that would comply with regulatory standards. The partnership of patient groups and researchers through research as an event may further elevate the role of patients and patient groups in PFDD.

There are certain challenges that need to be addressed for a wider implementation of research as an event. Some communities are less structured, and prior engagement patterns may not exist. More resources will be required in locating the active members of the community and establishing reliable communication channels. Some communities may be on the other end of the spectrum with a massive governing structure and operates under well-established bureaucratic traditions. Researchers may then have to go through a tedious process to acquire the complete buy-in 
of the community or they may encounter push back when attempting to install research as an event to a meticulously planned conference. Also, an event often follows a specific timeline. Communities or patient groups usually hold events at certain times of the year, which could potentially clash with the research timetable. Last but not least, with broader implementation, there comes the possibility of accommodating multiple research teams at one event. Coordination and careful planning will be needed for the different teams to operate smoothly without interfering with each others' objectives. ${ }^{36}$

\section{Acknowledgments}

We are grateful for the funding support from Prader-Willi Syndrome Clinical Trials Consortium to conduct the case study. John FP Bridges appreciates the funding support from the Patient-Centered Outcomes Research Institute (PCORI) Methods Program Award (ME-1303-5946).

\section{Author contributions}

All authors contributed toward data analysis, drafting and critically revising the paper, gave final approval of the version to be published, and agree to be accountable for all aspects of the work.

\section{Disclosure}

The authors report no conflicts of interest in this work.

\section{References}

1. Johnson FR, Beusterien K, Özdemir S, et al. Giving patients a meaningful voice in United States regulatory decision making: the role for health preference research. Patient. 2017;10:523-526.

2. Ho MP, Gonzalez JM, Lerner HP, et al. Incorporating patient-preference evidence into regulatory decision making. Surg Endosc. 2015;29(10): 2984-2993.

3. Ho M, Saha A, McCleary KK, et al. A framework for incorporating patient preferences regarding benefits and risks into regulatory assessment of medical technologies. Value Health. 2016;19(6):746-750.

4. The 21 st Century Cures Act (H.R. 34.). Natl. Institutes Heal. Reauthorization. Sec 2001. Available from: https://www.congress.gov/114/bills/ hr34/BILLS-114hr34enr.pdf. Accessed March 13, 2018.

5. Perfetto EM, Burke L, Oehrlein EM, Epstein RS. Patient-focused drug development: a new direction for collaboration. Med Care. 2015; 53(1):9-17.

6. The Food and Drug Administration. PDUFA Reauthorization Performance Goals and Procedures Fiscal Years 2018 through 2022. Available from: https://www.fda.gov/downloads/forindustry/userfees/prescriptiondruguserfee/ucm511438.pdf. Accessed March 13, 2018.

7. Mühlbacher AC, Juhnke C, Beyer AR, Garner S. Patient-focused benefit-risk analysis to inform regulatory decisions: the European Union perspective. Value Health. 2016;19(6):734-740.

8. Mühlbacher AC, Johnson FR. Giving patients a meaningful voice in European health technology assessments: the role of health preference research. Patient. 2017;10:527-530.

9. Frank L, Forsythe L, Ellis L, et al. Conceptual and practical foundations of patient engagement in research at the patient-centered outcomes research institute. Qual Life Res. 2015;24(5):1033-1041.
10. Hacker K. Community-Based Participatory Research. Thousand Oaks, CA: SAGE Publications; 2013.

11. Holkup PA, Tripp-Reimer T, Salois EM, et al. Community-based participatory research: an approach to intervention research with a Native American community. Adv Nurs Sci. 2004;27:162-175.

12. Hylton C. Patient engagement - the PaCER model. Trials. 2015;16:O2.

13. Mullard A. Patient-focused drug development programme takes first steps. Nat Rev Drug Discov. 2013;12(9):651-652.

14. U.S. Food and Drug Administration [webpage on the Internet]. Prescription Drug User Fee Act (PDUFA) - Externally-led Patient-Focused Drug Development Meetings. Center for Drug Evaluation and Research. Available from: https://www.fda.gov/forindustry/userfees/prescriptiondruguserfee/ucm453856.htm. Accessed March 13, 2018.

15. Food and Drug Administration [webpage on the Internet]. Patient Engagement Collaborative. Available from: https://www.fda.gov/ ForPatients/PatientEngagement/ucm506248.htm. Accessed March 13, 2018.

16. Terry SF, Terry PF, Rauen KA, Uitto J, Bercovitch LG. Advocacy groups as research organizations: the PXE International example. Nat Rev Genet. 2007;8(2):157-164.

17. Rabeharisoa V. The struggle against neuromuscular diseases in France and the emergence of the "partnership model" of patient organisation. Soc Sci Med. 2003;57:2127-2136.

18. Boon W, Broekgaarden R. The role of patient advocacy organisations in neuromuscular disease R\&D - the case of the Dutch neuromuscular disease association VSN. Neuromuscul Disord. 2010;20:148-151.

19. Furlong P, Bridges JFP, Charnas L, et al. How a patient advocacy group developed the first proposed draft guidance document for industry for submission to the U.S. Food and Drug Administration. Orphanet $J$ Rare Dis. 2015;10:82.

20. Smith SK, Selig W, Harker M, et al. Patient engagement practices in clinical research among patient groups, industry, and academia in the United States: a survey. PLoS One. 2015;10(10):e0140232.

21. Landy DC, Brinich MA, Colten ME, Horn EJ, Terry SF, Sharp RR. How disease advocacy organizations participate in clinical research: a survey of genetic organizations. Genet Med. 2012;14(2):223-228.

22. Uitto J. Patient advocacy organizations partner genetic research, and forge the agenda. Trends Mol Med. 2001;7:182.

23. Domecq JP, Prutsky G, Elraiyah T, et al. Patient engagement in research: a systematic review. BMC Health Serv Res. 2014;14:89.

24. Janssen EM, Segal JB, Bridges JFP. A framework for instrument development of a choice experiment: an application to type 2 diabetes. Patient. 2016;9(5):465-479.

25. Hollin IL, Caroline Young, Hanson C, Bridges JFP, Peay H. Developing a patient-centered benefit-risk survey: a community-engaged process. Value Health. 2016;19(6):751-757.

26. Concannon TW, Fuster M, Saunders T, et al. A systematic review of stakeholder engagement in comparative effectiveness and patientcentered outcomes research. J Gen Intern Med. 2014;29:1692-1701.

27. Mullins CD, Abdulhalim AM, Lavallee DC. Continuous patient engagement in comparative effectiveness research. JAMA. 2012;307: 1587.

28. Yancey AK, Ortega AN, Kumanyika SK. Effective recruitment and retention of minority research participants. Annu Rev Public Health. 2006;27:1-28.

29. Peay HL, Hollin I, Fischer R, Bridges JF. A community-engaged approach to quantifying caregiver preferences for the benefits and risks of emerging therapies for Duchenne muscular dystrophy. Clin Ther. 2014;36(5):624-637.

30. Shah SGS, Robinson I. Benefits of and barriers to involving users in medical device technology development and evaluation. Int J Technol Assess Health Care. 2007;23(1):131-137.

31. Bodison SC, Sankaré I, Anaya H, et al. Engaging the community in the dissemination, implementation, and improvement of health-related research. Clin Transl Sci. 2015;8(6):814-819.

32. Gul RB, Ali PA. Clinical trials: the challenge of recruitment and retention of participants. J Clin Nurs. 2010;19(1-2):227-233. 
33. Gross D, Fogg L. Clinical trials in the 21 st century: the case for participant-centered research. Res Nurs Health. 2001;24(6):530-539.

34. Aitken C, Power R, Dwyer R. A very low response rate in an on-line survey of medical practitioners. Aust N Z J Public Health. 2008;32(3): 288-289.

35. Roussos ST, Fawcett SB. A review of collaborative partnerships as a strategy for improving community health. Annu Rev Public Health. 2000; 21:369-402.

36. Patel MX, Doku V, Tennakoon L. Challenges in recruitment of research participants. Adv Psychiatr Treat. 2003;9:229-238.

37. Linden HM, Reisch LM, Hart A, et al. Attitudes toward participation in breast cancer randomized clinical trials in the African American community: a focus group study. Cancer Nurs. 2007;30(4):261-269.

38. Prinz RJ, Smith EP, Dumas JE, Laughlin JE, White DW, Barrón R. Recruitment and retention of participants in prevention trials involving family-based interventions. Am J Prev Med. 2001;20(1 suppl 1): $31-37$.
39. Foundation for Prader-Willi Research [homepage on the Internet] Available from: https://www.fpwr.org/. Accessed March 13, 2018.

40. Cassidy SB, Driscoll DJ. Prader-Willi syndrome. Eur J Hum Genet. 2009;17(1):3-13.

41. Goldstone AP. Prader-Willi syndrome: advances in genetics, pathophysiology and treatment. Trends Endocrinol Metab. 2003;15(1):12-20.

42. Schlernitzauer M, Bierhals AJ, Geary MD, et al. Recruitment methods for intervention research in bereavement-related depression. Five years' experience. Am J Geriatr Psychiatry. 1998;6:67-74.

43. Feldtkeller E, Bruckel J, Khan MA. Scientific contributions of ankylosing spondylitis patient advocacy groups. Curr Opin Rheumatol. 2000; 12(4):239-247.

44. Ahmed SM, Palermo A-GS. Community engagement in research: frameworks for education and peer review. Am J Public Health. 2010; 100(8):1380-1387.

\section{Publish your work in this journal}

Patient Preference and Adherence is an international, peer-reviewed, open access journal that focuses on the growing importance of patient preference and adherence throughout the therapeutic continuum. Patient satisfaction, acceptability, quality of life, compliance, persistence and their role in developing new therapeutic modalities and compounds to optimize clinical outcomes for existing disease states are major areas of interest for the journal. This journal has been accepted for indexing on PubMed Central. The manuscript management system is completely online and includes a very quick and fair peer-review system, which is all easy to use. Visit http://www. dovepress.com/testimonials.php to read real quotes from published authors.

Submit your manuscript here: http://www.dovepress.com/patient-preference-and-adherence-journal 